\title{
An Elective Training Program for Increasing Moral competence of Social Workers
}

\author{
Neveen saber Abd El-hakim (PhD)
}

Associate professor Faculty of Social Work, Helwan University

\section{Bassem Youssef Mohammed El-Moazen (PhD)}

Assistance professor, Faculty of Social Work, Helwan University 



\begin{tabular}{||lr||}
\hline The Egyptian Journal of Social Work (EJSW) & www.eisw.org \\
ISSN: 2356-9204 & Vol 1, No.5, January 2018 \\
\hline
\end{tabular}

\title{
An Elective Training Program for Increasing Moral competence of Social Workers
}

\author{
Neveen saber Abd El-hakim (PhD) \\ Associate professor Faculty of Social Work, Helwan University \\ Bassem Youssef Mohammed El-Moazen (PhD) \\ Assistance professor, Faculty of Social Work, Helwan University
}

\begin{abstract}
:
Moral competence with its different dimensions are considered the life force of a person and the basis of his moral being and his interaction with his society and the facts of his life. A society without morals is like a construction without foundation. Moral competence is an important factor in the individual's ability to achieve professional and social harmony with the surrounding environment and society. It acts as the regulator for a person's behavior, to inhibit his tendency for disruption, aggression, or violation of laws. The study aims to test the effectiveness of the elective model in developing moral competence between social workers, colleagues and supervisors at work. The study sample consisted of (30) social workers divided into two groups, one experimental and the other a control group, the study detailed the dimensions and components of these competencies. It also presented the procedural steps for developing the social workers' moral competencies, transferring this knowledge and demonstrating the competencies through their behavior, thus resulting in a better psychological status for social workers socially, morally, behaviorally, and professionally, this study belong with quasi-experimental type that aims to examine the relationship among two main variables, The results of the study confirmed the validity of the study hypotheses, including the existence of There are statistically significant differences among the mean scores of the pre-and post-testing on the competence scale in favor of the experimental group, There are statistically significant differences among the mean scores of the experimental and control groups in the post-testing of the moral competence scale dimensions. The study confirmed the validity of this hypothesis.

Key words: elective training program, empathy, moral competencies, respect, self-control, tolerance, vigilant conscience.
\end{abstract}




\section{The Egyptian Journal of Social Work (EJSW) www.eisw.org \\ ISSN: 2356-9204 Vol 1, No.5, January 2018}

\section{Introduction:}

Our society is currently undergoing transformations that have encompassed many aspects of its social, economic and cultural life. These transformations have had a great impact on many of the prevailing customs, trends and values. Morality, humanitarian behavior, cooperation tendencies, and tolerance between individuals have been strikingly weakened.

The moral aspect is associated with many personnel and mental traits and abilities (Hoffman M., 1970, p. 122). Moral competence is considered the cornerstone of the social workers' credibility and behavioral commitment, making them an exemplary and dignified figure between his clients, colleagues and superiors at work. This was confirmed by the results of study El Shemari (2007): The study was designed to measure the correlation between moral competence and mutual social trust. The study sample was 400 students randomly selected from eight schools in the University of Baghdad, four of which were specialized in humanities, the other four specialized in sciences. The researcher built a moral competence scale for university students, based on Borba's moral competence theory. The study found that university students possess moral competence, and that there is a statistically significant positive correlation between moral competence and mutual social confidence. The study also found no difference in moral competence according the gender variable (male - female) and specialization (scientific - humanities).

Moral competence refers to the e $\square$ ective orientation to perform altruistic behaviors towards others and the ability to judge moral issues logically, consistently, and at an advanced level of development. Promotion of moral competence means fostering the development of justice judgment and altruistic behavior in social workers. It is the goal of education to help social workers develop the value of universal justice and universal love (Hing Keung Ma, 2014, p. 1259).

Moral behavior is the result of at least four component processes: (1) identifying a situation as a competence: altruism and moraljudgment development moral problem, (2) figuring out what one ought to do and evaluating possible plans of action, (3) evaluating how the various courses of action serve moral and no moral values and deciding which action will be pursued and (4) executing the plan of action (Mahasneh, Ahmad2014, p: 1265). 


\section{The Egyptian Journal of Social Work (EJSW) www.ejsw.org \\ ISSN: 2356-9204 Vol 1, No.5, January 2018}

Moral competence is an important factor in determining the daily interactions of individuals with those around them in the various life domains. Where moral competence is efficient, it becomes a factor of psychological harmonization on the personnel and societal levels (Shawki, 2002, p. 17). The decline in efficiency of moral competence leads to failure in social life, recurring pressures and hardships, and failed personnel relationships (Golman, 2000, p. 165). This was confirmed by the results of study Borba (2001): The purpose of the study was to measure the correlation between moral competence and self-esteem among adolescents. The study was conducted on a sample of (200) high school students in New York City. The researcher built a moral competence scale that consisted of seven areas, which the researcher treated as essential components of one subject rather than separate issues. The study results show that they're a statistically significant correlation between moral competence and self-esteem among high school adolescent students (Borba, 2001, p. 8).

Generally, the concept of moral competence refers to an abundance in acquired behaviors that serve different purposes, including supporting interaction with others, facilitating initiatives, continued communication, filling the need for satisfaction in professional relationships and social contexts, and reducing negative social reactions as a result of compatibility with expected social behavior (El Gharib, 2003, p. 41).

Moral education is strengthened through practice and good example. Through practice, we raise our children to follow our example. Our mission is flawed if the values of science and education are not reflected in our behavior. What do we say, what do we feel in our hearts, and how do we behave? Where are we on the scale of good example? This is the question for our society (El Rashid, 2002, pp: 810). This was confirmed by the results of study Kindlon and Thompson (2002): The study aimed to reveal the correlation between moral competence and the intelligence levels among pre-school children, and to measure the differences in the levels of moral competence according to the gender variable. The study sample consisted of (1000) children in New York City. The study findings revealed that there is a positive correlation between moral competence and the general IQ levels among pre-school children. In addition, one in ten children exhibited problems in moral competence despite their normal or even superior intelligence. This is because intelligence is not considered an absolute criterion for acquiring moral competence 


\section{The Egyptian Journal of Social Work (EJSW) www.ejsw.org \\ ISSN: 2356-9204 Vol 1, No.5, January 2018}

unless it has been deliberately and continuously built and strengthened. The findings also revealed a positive difference in moral competence towards females according to the gender variable. And the study of Shehata (2008): The purpose of the study was to identify the relationship between moral intelligence in the school and family environments among first secondary students. The study sample was 420 male and female students from Minia Governorate in Egypt. The researcher built a moral intelligence scale that incorporated the testing of the family's social environment. The study found no effect of the gender variable nor the rural/urban variable on moral intelligence, but a positive correlation existed between moral intelligence and the family's social environment.

Thus, developing an individual's moral competence supports his inner sense or right and wrong, and helps him address the moral pressures and challenges that he faces. In general, as Michel Borba points out, moral intelligence (or moral competence) means "the ability to distinguish right from wrong and having ethical standards on which an individual act. This is reached by combining several essential virtues: empathy, vigilance of conscience, self-control, respect, compassion, tolerance, and justice (E1 TaeI, 2010, pp: 28-30). This was confirmed by the results of neither study Nor Hafizah $\mathrm{NH}$, 2012: The purpose of this research was to identify the levels of morality among a group of Malaysian youths using an adapted version of the Moral Competency Index (MCI) through a pilot study. The hypotheses were 1) there is no difference between genders with regard to moral competencies and 2) there is no difference between religion affiliations with regard to moral competencies. The MCI was also examined for its internal reliability and factor analysis. The sample comprised of 75 youths (male $=19$, age mean 22.00 SD 4.69; female $=55$, age mean 20.49 SD 4.52; unknown gender $=1$ ) staying in Kelantan. For hypothesis one, out of the ten dimensions, gender difference was only significant for "admitting mistakes and failures". Factor analysis established ten dimensions of moral competencies. The findings of this study have implications for moral education and as a rehabilitation effort for social ills among the youth. And the study of Kamila Št'astná Roudnice and Labem (2016): The purpose of this paper was to present the results of the study undertaken to examine this program. During an academic year in school, this method was implemented in ethics classes for Czech teenagers $(\mathrm{N}=42)$. Moral competence was investigated by MCT (Moral Competence Test) in a 


\section{The Egyptian Journal of Social Work (EJSW) www.eisw.org \\ ISSN: 2356-9204 Vol 1, No.5, January 2018}

research group and two control groups before and after the process. However, the results show that there was no significant impact on moral competence KMDD seems to foster different aspects of morality.

Moral Competence: Borba defines moral competence as the ability of the individual to understand right from wrong, and to acquire moral convictions that allows him/her to act correctly based on possessing seven virtues that guide his/her behavior: empathy, conscience, self-control, respect, kindness, tolerance, and fairness (Borba, 2001, p.4).

The Operational definition of moral competence is the total score that a social worker receives after responding to the moral competence scale designed for this study.

Moral Competence Dimensions: Empathy: How to identify with and feel for other people's concern Empathy, or understanding, is the main virtue of moral intelligence (moral competence). It means "the ability to understand the concerns of others and feeling them. The person becomes more sensitive towards the needs and feelings of other people, understands their circumstances and helps them, and recognizes the emotions accompanying the feelings of pain and joy. This prevents the person from treating others with cruelty, indifference, or lack of concern for their feelings (Khalil, 2011, p. 122). The procedural definition of empathy in this study is the ability of the social worker to understand the interests, needs, and feelings of clients, comprehend their emotions and circumstances, and provide them with assistance. Vigilant Conscience: How to know the right and descent way to act? Conscience is the ideal self or the individual's inner supply of values and ideals that monitor the performance of the general or social self. It makes the individual distinguish among right and wrong, and instigates feelings of guilt or conscience pricking when he or she deviates. It is considered the cornerstone for the development of basic virtues such as dignity, feeling of responsibility, and equity (EL Zoheiry, 2013, pp: 9 - 12). The procedural definition of conscience in this study is the ability for self-control, and instigation the self to distinguish among right and wrong, to identify the correct path, and to feel guilty for deviation off the path. SelfControl: How to regulate your thoughts and actions to act the way you know and feel is right? Self-monitoring helps individuals regulate their behavior and recognize their contradiction. It is considered the moral muscle that temporarily stops harmful actions through

\section{1}




\section{The Egyptian Journal of Social Work (EJSW) www.eisw.org \\ ISSN: 2356-9204 Vol 1, No.5, January 2018}

providing us with the few extra seconds we need to recognize the potential consequences of our actions, and reign them accordingly (Al Ayoub, 2006, p. 13). The procedural definition of self-control in this study is the ability of an individual to organize his thoughts and behavior, to modify his motives, and use his wisdom to control them, and stop harmful actions because of recognizing their potential consequences. Respect: How to value others by treating them in a courteous and considerate way? Respect means treating others in the way you would like them to treat you, and to love for them what you would love for yourself. Respectful people are more concerned with the rights of others. They think positively of other people and are more considerate towards them. Self-respect and respect for others is the cornerstone of preventing violence, injustice and hatred (Gullickson, T., 2004, p. 17). The procedural definition of respect in this study is the ability to treat others in the way that the individual prefers to be treated. It is making others feel important and appreciated in a friendly and tolerant manner and recognizing their rights. Tolerance: How to respect the dignity and rights of other persons even those whose beliefs and behaviors differ with our own? Tolerance is an important moral virtue that helps to eliminate hatred, violence and hatred. It is to treat others with kindness, respect and understanding. It also means respecting differences and the conviction that all people deserve to be treated with love, justice and respect, regardless of how much we agree to their beliefs or behaviors. People are not born with hatred. Bias and prejudice are acquired or developed when actions for spreading and promoting tolerance among people are missing, As Borba (2003) demonstrates, tolerance two manifestations: A) Respect for human dignity and a person's right to make his own moral choices, while they do not affect the rights of others; and trying to persuade others of the best way without controlling or imposing our views, or restricting their freedom. B) Tolerance is an appreciation for the rich human diversity and recognizing the positive results of that diversity. It is the conviction that each person is unique, which enables us to agree on the most controversial issues and to live with our deepest differences while we continue to discuss them. (Borba, 2003, pp: 232-233). The procedural definition of tolerance in this study is the respect for people's difference, and the respect for all people's dignity and rights regardless of differences in beliefs and behaviors. 


\section{The Egyptian Journal of Social Work (EJSW) www.eisw.org \\ ISSN: 2356-9204 Vol 1, No.5, January 2018}

The importance of this study is derived from the importance of moral competence as one dimensions of a sound personnelity. The effects of these dimensions are evident in all aspects of the life of an individual. It also determines the individual's growth and the quality of his/her future relations. Moral competence is considered one solid foundation in society, contributing to its building, reliability, and sustainability. It promotes the rule of truth, virtue, and charity, which, in turn, is reflected on society's production and positivity as well those of the social workers in any social work field. The theoretical importance of this study lies in clarifying the concept and components of moral competence to the social worker, its methods of development, and its role in the sound formation of social workers, who are responsible for conducting several tasks. Thus, the level of their moral competence is reflected on their productivity and their interactions with other members of the society. The practicable importance of this study lies in its identification and description of the level of moral competence between social workers in the field youth care. The study will help academics develop training and councils program to address and modify social workers' behavioral patterns which do not demonstrate adherence to the dimensions of moral competence. It will also help social workers, academics, and decision makers review the curricula and their contents, especially in terms of moral intelligence, to ensure that said curricula work to instill and develop the social workers' moral virtues, thus enabling them to adapt to society.

Considering that the elective approach is an important scientific approach, which can be used to increases the moral competence of social workers, Elective Approach can be defined: The elective approach in social work is applied through providing social workers with the opportunity to choose what they deem suitable from the professional methods presented. Those methods are built on theories and approaches varying in objectives, type, duration, and assessment methods (Suleiman and Abdel-Majid, 2005, p. 25). This was confirmed by the results of study Seddik (2000): The purpose of the study was to practice an elective approach dealing with the crisis of disease between patients. The study proved the effectiveness of this approach dealing with patients. The study depended on the crisis theory, the cognitive behavioral therapy, focusing on tasks, and the effectiveness of being occupied with tasks in mitigating problems. And the study of Al-Taifi (2004): The study aimed to use elective 


\section{The Egyptian Journal of Social Work (EJSW) www.ejsw.org \\ ISSN: 2356-9204 Vol 1, No.5, January 2018}

techniques to develop children's creative thinking abilities. The study asserted the effectiveness of the elective style in developing creativity among children. The study also found that activity help develops the child's self-awareness and increase his experiences.

The elective approach is also defined as a coordinated system of therapeutic techniques in which each technique follows its own specific therapeutic theory. The integrative manner in which the selection of each technique occurs contributes to addressing one aspects of the individual's personality (Azab, 2002, p. 5).

The definition of the elective approach for this study: The elective approach is defined as a well-coordinated practice in terms of planning, implementation, and evaluation, which is derived from the integrated elective approach. It encompasses varied methods and techniques that are consistent with the program's phase, activities and procedures. The approach is applied in the form of interviews and professional settings, in a safe social and psychological environment that allows for social participation and fruitful interaction. The elective approach aims to encourage active positive behavior and positive feelings, to provide the client with skills needed for forming good relationships and amending bad ones, to change illogical aspects into logical ones, and to change the negative mental self-image into a positive one. This was confirmed by the results of study Mansour (2008): The purpose of the study was to test a proposed program from an elective approach perspective to realize social protection for children at risk. The results asserted the effectiveness of the elective style in realizing social protection for children at risk. And study of Gamal (2013): The purpose of the study was to implement a preventive program from an elective perspective to prevent psychological harassment between nurses; the results demonstrated a statistically significant positive correlation among applying a preventive program from an elective perspective and prevention.

Theories and Methods on which the Elective Approach depends: Since all theories forming the elective approach does not consider a specific technique or method as the best, but rather see the effective therapeutic method as that which suits the client, his/her needs, and the type or level of his/her problems. Selecting the techniques to use for therapy is based on this consideration. Using elective approach in therapy is based on the principal of individuality and the efficiency and expertise of the therapist. This allows the therapist to choose the most suitable technique to the situation and which could achieve the 


\section{The Egyptian Journal of Social Work (EJSW) www.eisw.org \\ ISSN: 2356-9204 Vol 1, No.5, January 2018}

objectives of therapy. This was confirmed by the results of study of Kamal (2017): The purpose of the study was to assess the effectiveness of the elective style in reducing violent behavior between secondary school students. Results asserted the effectiveness of the elective style in reducing the frequency of violent behavior among students and their peers, and among students and teachers, in previous studies, we found that there was a lack of moral competence, and a training program was put in place to increase the ethical efficiency of the social workers.

Study Hypotheses: First Hypothesis: There are statistically significant differences among the mean scores of the pre-and posttesting on the moral competence scale, with positive significance in favor of the experimental group at 0.05 level. Second Hypothesis: There are statistically significant differences between the mean scores of the experimental and control groups in the post-testing of the moral competence scale dimensions. Third Hypothesis: There are no statistically significant differences among the mean scores of the preand post-testing of the control group on the moral competence scale.

Professional Intervention Training Program (building the elective approach to increase the moral competencies of social workers).

The Program Objectives: Increasing the moral competence of social workers, which includes empathy, conscience, respect, selfcontrol, and tolerance, through using the elective approach, which is based on methods and strategies that are derived from both cognitive and behavioral therapy, and psychological intervention, and concerned the tasks.

Duration: weekly interviews over the period of three months.

\section{Stages of professional intervention:}

1- Starting Stage, which includes: A) Applying the scale on the study sample, which was distributed using the simple random methods on two groups. One group was experimental and the other a control group. The sample was chosen based on pre-set criteria for choice and communication with the study community. B) Setting an oral contract with the experimental group clarifying the number of interviews and their purpose, the duration of the program, and the location for conducting the interviews.

2- Planning Stage, which includes: A) Determining the level of moral competence between the study cases. B) Planning for addressing any challenges that might face the cases or the Authors.

\section{5}




\section{The Egyptian Journal of Social Work (EJSW) www.ejsw.org \\ ISSN: 2356-9204 Vol 1, No.5, January 2018}

3- Implementation Stage, which includes: A) Conducting a group interview for the study cases to explain the objectives of professional intervention, the theories used in the study, and discussing ways to address expected difficulties during the implementation. B) Conducting individual interviews for each case to increase their moral competence through selected techniques that suit each individual case.

4-Termination Stage, which includes: A) reviewing the achieved objectives and evaluating the professional intervention. B) Reapplying the moral competence scales identify the extent of improvement achieved as a result of carrying out the professional intervention program. C) Comparing the results of the pre-and post-testing to determine the level of increase in moral competence.

\section{Strategies which Used in the Program: include the following.}

Behavioral Modification Strategy: This strategy is based on the arrangement of educational and training experiences in a manner that allows for the formation of behavior that is precisely determined through methods of support and modification. Acquiring Knowledge and Thought Processes Strategy: This strategy emphasizes the acquisition of knowledge and different ways of thinking. It is also concerned with examining, assessing, and diagnosing problems and solving them. And Personnel Growth Strategy: The strategy focuses on activities that lead to personnel growth, self-realization, and supporting social workers in understanding their strengths and weaknesses. And Persuasion strategy and Empowerment strategy and Education and training strategy which are used in the program.

Tactics used by the Authors in the professional intervention program: the Authors were used a lot of tactics in this program such as: Explanation and clarification for the research objectives and the professional intervention program for the officials of the Youth Care Departments and the social workers working in those departments. And Gathering, analyzing, and interpreting the data obtained through the conducted individual and group interviews, tactics of Communication between the two Authors, the Youth Care Department, and the social workers working in those departments and persuasion tactic: by reducing the sense of social specialists of the possibility of exposure to professional threats, especially without skills of moral competence. Gain trust and mutual respect tactic: by working to establish a good relationship with the social workers under 


\begin{tabular}{||lr||}
\hline The Egyptian Journal of Social Work (EJSW) & Www.ejsw.org \\
ISSN: $2356-9204$ & Vol 1, No.5, January 2018 \\
\hline
\end{tabular}

study based on mutual respect for the implementation of the program of professional intervention.

The therapeutic methods of the intervention program: The Authors chose the therapeutic methods through applying the elective style as follows:

A- Psychological support techniques: They include the following: Emotional Unloading to alleviate the psychological suffering caused by occupational exhaustion and to reduce the pressures associated with work and administrative burdens. Respecting the social workers' feelings through assessing the circumstances, providing them with support, clarifying the seriousness of accumulated pressures and to affects their relationship with others, and clarifying the ensuing social and psychological problems.

B- Cognitive methods: They include the replacement of wrong ideas with logical statements and objectives through providing a new perception of the misconceptions that social workers believe play a significant role in directing their behavior and stirring their emotions, such as Clarification, Logical discussion, Cognitive reconstruction, Confrontation, Persuasion, Urging commitment.

C - Emotional methods: the Authors used a lot of emotional methods to increase the moral competencies such as: Meditation, and insight, and distraction, Patience through difficulties.

D- Behavioral methods: Positive reinforcement: through providing social workers with rewards and moral support such as commending behaviors, attitudes, and feelings that they express while exercising their roles. Modeling: directing social workers to follow a relatively exemplary model in commitment, respect, tolerance, and personality that is rarely abused by others as well as the choice of a good moral and ethical example guide them. Training on Problem Solving: through training social workers on new behavioral patterns related to interactions and social relations. Role Play: through guiding social workers to play the roles of their clients, colleagues, or supervisors. Homework: through writing personnel reports which represent the connection between each interview and the preceding and following Interviews.

E- Spiritual methods: These include: Strengthening different types of religious practices like prayer and reading the Koran, which is reflected on social worker's appearance, behavior, and interactions with other, because of the important connection between religion and faith and people's behavior and interactions with others. 


\section{The Egyptian Journal of Social Work (EJSW) www.ejsw.org \\ ISSN: 2356-9204 Vol 1, No.5, January 2018}

Reinforcing positive traits: such as transparency, openness and honesty Religious guidance and religious awareness.

F- Professional methods: To achieve the study objectives, the Authors relied on interviews with some social workers social to ensure their participation in the professional intervention program and activities, and to benefit from their experiences and opinions in this area. The Authors also used Interviews as a method for providing an opportunity for dialogue, discussion, and participation specialists in achieving the goal of the research, to ensure their participation in the program of professional intervention and activities and to benefit from their experiences and opinions in the discussions. Other methods were used in addition on a case-by-case.

Roles for Implementing the Professional Intervention Program: there are used in this program a lot of roles such as: The role of the director: Providing social workers with advice and guidance, and recommendations that help their decision-making; providing professional opinions that help channel behaviors in a specific direction; and providing social workers with booklets on effective communication and the problems related to negative communication. The role of the teacher: Teaching social workers how to improve their moral competence level, how to deal with clients, colleagues, and supervisor, and how to form sound social relationships that positively affect the level of moral competence; helping social workers acquire skills such as problem solving; increasing their participation in activities; and helping them change their attitudes. The role of the guide: Educating the experimental group about themselves; and helping them achieve their objectives realistically, thus helping them improve their work performance, And The role of the encourager and the role of the enabler, and the role of the expert, and the role of the clarifier.

Skills Applied by the Authors during the Preliminary Phase: we used in this program a lot of skills in this program such as: Communication Skills: Contacting the Youth Care Department and its social workers to assess the possibility of applying the moral competence scale, to support and qualify social workers and develop their moral competence, Influencing Others: Sensitizing the Youth Care Department and its social workers to the importance of cooperation with the Authors, and convincing them that the professional intervention program will contributes to strengthening 
The Egyptian Journal of Social Work (EJSW) www.ejsw.org

ISSN: 2356-9204

Vol 1, No.5, January 2018

and improving their professional level and moral competencies. Gathering and interpreting information Skill: By gathering as much information as possible about the social workers, quantitative information or qualitative information to help us prepare the program, And Active Listening Skill, and Persuasion Skill and Cooperation Skill and Coordination Skill.

rogram Evaluation Stage: The purpose of this stage to evaluate the professional intervention program using the following tools: The moral competence scale: Post-testing was conducting with the control and experimental groups and results were compared with the pretesting, and Analyzing the content of the various professional group interviews.

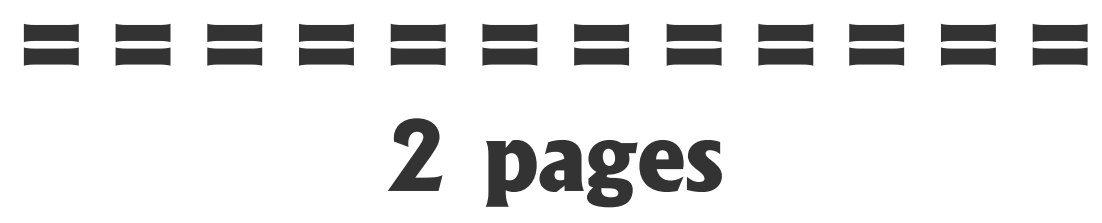




\section{The Egyptian Journal of Social Work (EJSW) www.ejsw.org \\ ISSN: 2356-9204 Vol 1, No.5, January 2018}

\section{Methodology:}

This study belongs with quasi-experimental type that aims to examine the relationship among two main variables. The first is an independent variable using the elective approach, and the second is a dependent variable of developing the moral competence of the social workers. The study followed a quasi-experimental approach based on two groups, an experimental group and a control group. The data was collected through applying the scale that was specifically designed for this study. Following data collection, appropriate statistical analysis was carried out. The Study Society consisted of social workers in the field of youth care at the University of Helwan, whose number amounted to 85 persons. From among the social workers, two groups of 15 persons each were randomly chosen, one experimental, and the other is a control group. The sample of the study consisted of thirty social workers from the youth care department, divided into two groups, one experimental and the other a control group. Each group consisted of fifteen members. All participants provided written approvals for taking part in the professional intervention program. The study found no statistically significant differences among the mean scores of the experimental and control groups on the moral competence scale in pretesting. The arithmetic mean of the experimental groups was (355.40), with a standard deviation of (52.20). The arithmetic mean of the control group was (352.06), with a standard deviation of (56.31). The value of $\mathrm{T}$ was non-significant $(\mathrm{T}=.407)$, which shows consistency between the experimental and control groups.

The characteristics of study sample the percentage of male/female representations in the control group was $76.7 \%$ for males and $23.3 \%$ for females. The percentages were $80 \%$ males and $20 \%$ females in the experimental group. And The average age of the control group was $2.46 \%$, and the average age of the experimental group was $2.73 \%$ using T. TEST. And The distribution of social workers by academic degree in the control group was BA 73.3\%, MA $13.3 \%$, and $\mathrm{PhD} .13 .3 \%$, while the distribution for the experimental group was $\mathrm{BA}$ $53.3 \%$, MA $26.7 \%$, and $\mathrm{PhD} 20 \%$. And The percentages of years of experience of social workers in the experimental group were $26.7 \%$ less than three years of experience, $20 \%$ from 3 to 6 years of experience, $6.7 \%$ from 6 to 9 years of experience, and $46.9 \%$ more

\section{2}




\begin{tabular}{||lr||}
\hline The Egyptian Journal of Social Work (EJSW) & Www.ejsw.org \\
ISSN: $2356-9204$ & Vol 1, No.5, January 2018 \\
\hline
\end{tabular}

than 9 years of experience. For the control group, the percentages were $13.3 \%$ less than 3 years of experience, $33.3 \%$, from 3 to 6 years of experience, $20 \%$ from 6 to 9 years of experience, and $33.3 \%$ more than 9 years of experience. The mean years of experience of the control group was $2.73 \%$ with a standard deviation of 1.099 , while the mean years of experience of the experimental group was $2.73 \%$ and a standard deviation of 133.4 using T. TEST. Most of the social workers in the experimental and control groups $(73.3 \%)$ have received theoretical preparation on moral competence, while $26.7 \%$ have not.

Social workers in both groups $(100 \%)$ have not participated in any training courses on moral competence, none of the social workers.

This study was applied in the Department of Youth Care at Helwan University in Cairo, Egypt. It was chosen based on the following justifications: written approvals of respondents for participating in the professional intervention program, and the cooperation with Authors in implementing the study. The study was implemented from 1/11/2016 until 31/1/2017. The professional intervention program was implemented over a period of three months through weekly interviews. And this study tools were limited to the moral competence scale for social workers, which comprised a several.

A) The Scale Dimensions: The dimensions were set in light of Borba's theory, which was used as a theoretical framework. Five areas were identified: conscience, self-control, empathy, respect, and tolerance.

B) Composing the Statements of the Scale: In the light of the definitions of the study dimensions, and after reviewing previous studies and scales on moral competence that depended on Michelle Borba's theory, such as (El Shammari 2007) and (Borba, 2001), the statements were comprised. (130) statements were comprised. covering all the aspects of the study,26 statements per aspect. The statements were all in first person form, each having one interpretation only.

C) Face Validity: The statements were presented to a group of social work specialists to assess their validity, relevance, formulation accuracy, suitability to the age of the research sample. The specialists were asked to modify, add, or remove what they deemed necessary. More than $80 \%$ of the statements were approved for validity, and 15 statements were removed. The number of statements in moral competence scale became 115 statements,

\section{3}




\begin{tabular}{|lr|}
\hline The Egyptian Journal of Social Work (EJSW) & www.ejsw.org \\
ISSN: 2356-9204 & Vol 1, No.5, January 2018 \\
\hline
\end{tabular}

Table (2)

Internal consistency between scale variables and degree of scale as a whole

$N(15)$

\begin{tabular}{|c|c|c|c|}
\hline $\mathbf{n}$ & Dimensions & \begin{tabular}{|c} 
Pearson \\
Correlation
\end{tabular} & $\begin{array}{c}\text { Significance } \\
\text { (2-tailed) }\end{array}$ \\
\hline$\overline{1}$ & empathy & 0.921 & *** \\
\hline 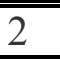 & "Vigilant conscience & 0.953 & *** \\
\hline$\overline{3}$ & respect & 0.939 & *** \\
\hline 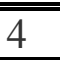 & Self-control & 0.962 & *** \\
\hline 5 & tolerance & 0.971 & *** \\
\hline
\end{tabular}

this table clear from the previous table that the dimensions of the tool function at a significant level (0.01) for each dimension separately, and then achieve the level of confidence in the tool and rely on the results, and the Authors can rely on the study.

D) reliability of the scale: The Authors used the test-retest method to measure the reliability of the scale. This method is used to measure a group of individuals similar to the same characteristics of the study sample and then to apply the same tool to the same individuals at a time interval of approximately 15 days. Each individual applied the tool to a degree in the first application, then a degree in the second application, and through some statistical methods calculate the reliability of the tool, and the Authors calculated the reliability through the application to the number (15) of the social workers working in youth centers, First, and then re-test after (15) days of application For the first to calculate the correlation coefficient between the two applications to determine the coefficient of persistence of the form. The Authors used the Pearson correlation coefficient to calculate the correlation. 


\begin{tabular}{||lr||}
\hline The Egyptian Journal of Social Work (EJSW) & Www.ejsw.org \\
ISSN: $2356-9204$ & Vol 1, No.5, January 2018 \\
\hline
\end{tabular}

Table (3)

Demonstrates correlation coefficients between the first and second applications on the selected sample

\begin{tabular}{|c|c|c|}
\hline $\mathbf{n}$ & Dimensions & Correlation coefficient \\
\hline 1 & empathy & $0.978 * *$ \\
\hline 2 & Vigilant conscience & $0.873 * *$ \\
\hline 3 & respect & $0.995 * *$ \\
\hline 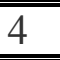 & Self-control & $0.588 * *$ \\
\hline 5 & tolerance & $0.755 * *$ \\
\hline
\end{tabular}

This Table shows the correlation coefficient of the first dimension (0.978) which is the correlation coefficient $\mathrm{D}$ at a significant level $(0.01 \%)$. The correlation coefficient of the second dimension (0.873) is the correlation coefficient $\mathrm{D}$ at a significant level $(0.01 \%$ The correlation coefficient for the third dimension $(0.995)$ was the correlation coefficient $\mathrm{D}$ at a significant level $(0.01 \%)$. The correlation coefficient for the fourth dimension $(0.855)$ was the correlation coefficient D at a significant level $(0.01 \%$ For the fifth dimension $(0,755)$ and correlation coefficient $\mathrm{D}$ at a significant level $(0.01 \%)$, which reassures the Authors to the availability of an appropriate degree of confidence and rely on the measure in measuring the moral competencies of the social workers which working in youth care.

Study Procedures: To implement the study, the following steps were taken:

1- Designing the study scale (moral competence scale), and finalizing the scale after verifying its validity and reliability. 2- Identifying the study community and sample, and choosing the department for youth care for implementation. 3- Distribution of the scale among the study sample, the researcher personally performed this task.4Applying the study on two groups, the experimental group and the control group, pre-program implementation, and then reapplying the study post program implementation with the experimental group.5-Extracting responses from 30 survey forms, processing the responses using the SPSS statistical package, and providing the scale with weights $(5,4,3,2,1)$. 


\begin{tabular}{||lr||}
\hline The Egyptian Journal of Social Work (EJSW) & www.ejsw.org \\
ISSN: $2356-9204$ & Vol 1, No.5, January 2018 \\
\hline
\end{tabular}

Study Results: which related Hypothesis of this study:

The result of First Hypothesis: There are statistically significant differences among the mean scores of the pre-and post-testing on the competence scale in favor of the experimental group cases.

Table (4)

Demonstrates the significance of the differences between the preand post testing for the experimental group on the dimensions of the moral competence scale using the T. TEST

\begin{tabular}{||c|c||c||c||c||c||c||}
\hline \hline Testing & N & Mean & $\begin{array}{c}\text { Std. } \\
\text { Deviation }\end{array}$ & T & $\begin{array}{c}\text { Sig. (2- } \\
\text { tailed) }\end{array}$ & Significance \\
\hline \hline Pre-Testing & 15 & 355.40 & 52.20 & $* * 8.892$ & .000 & Significant \\
\hline \hline Post-Testing & 15 & 422.13 & 31.77 & & & \\
\hline
\end{tabular}

The table shows the existence of statistically significant differences among the mean scores of the pre-and post-testing of the experimental group cases on the moral competence scale. The arithmetic mean of the pre-testing for the experimental group was (355.40) with a standard deviation of (52.20), while the arithmetic mean of the post-testing was (422.13) with a standard deviation of (31.77). The value of $\mathrm{T}=(* * 8.892)$, which is significant. This confirms the validity of the hypothesis that there are statistically significant differences among the mean scores of the pre-and posttesting of the experimental group cases on the moral competence scale.

The result of second hypothesis: There are statistically significant differences between the mean scores of the experimental and control groups in the post-testing of the moral competence scale dimensions, in favor of the experimental group.

Table (5)

Demonstrates the significance of the differences between the post testing for the experimental and control groups on the dimensions of the moral competence scale using the T. TEST

\begin{tabular}{|l|c|c|r|r|r|l|}
\hline \multicolumn{1}{|c|}{ Testing } & N & Mean & $\begin{array}{c}\text { Std. } \\
\text { Deviation }\end{array}$ & T & $\begin{array}{c}\text { Sig. (2- } \\
\text { tailed) }\end{array}$ & Significance \\
\hline $\begin{array}{l}\text { Control } \\
\text { Group }\end{array}$ & 15 & 353.40 & 51.53 & $* * 7.611$ & .000 & $\begin{array}{l}\text { Significant } \\
0.01\end{array}$ \\
\cline { 1 - 5 } \\
$\begin{array}{l}\text { Experimental } \\
\text { Group }\end{array}$ & 15 & 422.13 & 31.77 & & & \\
\hline
\end{tabular}




\section{The Egyptian Journal of Social Work (EJSW) www.eisw.org \\ ISSN: 2356-9204 Vol 1, No.5, January 2018}

The results of the previous table show that there were statistically significant differences between the mean scores of the experimental and control groups in the post-testing of the moral competence scale dimensions, which were in favor of the experimental group. The arithmetic mean of the post-testing for the control group was 353.40, with a standard deviation of (51.53), while the arithmetic mean of the post-testing for the experimental group was (422.13), with a standard deviation of (31.77). The value of $\mathrm{T}=$ (7.611), which is significant at 0.01 significance level. This confirms the validity of the hypothesis that there are statistically significant differences between the mean scores of the experimental and control groups in the post-testing of the moral competence scale dimensions.

The results of third hypothesis: There are no statistically significant differences among the mean scores of the pre-and posttesting of the control group on the moral competence scale.

Table (6)

Demonstrates the significance of the differences between the preand post testing for the control group on the dimensions of the moral competence scale using the $T$. TEST

\begin{tabular}{|l|c|c|c|c|c|c|}
\hline Testing & $\mathbf{N}$ & Mean & $\begin{array}{c}\text { Std. } \\
\text { Deviation }\end{array}$ & $\mathbf{. 8 2 6 T}$ & $\begin{array}{c}\text { Sig. (2- } \\
\text { tailed) }\end{array}$ & Significance \\
\hline Pre-Testing & 15 & 352.07 & 56.31 & .423 & .826 & $\begin{array}{c}\text { Non- } \\
\text { Significant }\end{array}$ \\
\hline Post-Testing & 15 & 353.40 & 51.53 & .423 & & \\
\hline
\end{tabular}

The table shows that there were no statistically significant differences among the mean scores of the pre-and post-testing of the control group cases on the moral competence scale. The arithmetic mean of the pre-test was (352.07) with a standard deviation of (56.31), while the arithmetic mean of the post-testing was (353.40) with a standard deviation of (51.53). The value of $T$ was $(T=423)$ which is not a significant value. This indicates no statistically significant differences exist among the mean scores of the pre-and post-testing for the cases in the control group on the moral competence scale.

Discussion:

There are statistically significant differences between the mean scores of the pre-and post-testing on the competence scale in favor of the experimental group. The study confirmed the validity of the first hypothesis. This may be due to the suitability of professional intervention from an elective perspective, with its strategies and therapeutic methods, for addressing this problem. It may also be due

\section{7}




\section{The Egyptian Journal of Social Work (EJSW) www.eisw.org \\ ISSN: 2356-9204 Vol 1, No.5, January 2018}

to the flexibility of the elective approach that allows for the selection of methods that suit the nature of the situation. This correspond to the studies of Norhafizah (2012), Hassan Ali Hassan (2000), and Mahasna Ahmad (2014). The studies confirmed that therapeutic approaches and counsel programs could contribute to the development of moral competence between youth, which is positively reflected on their social relationships, their awareness of different situations and methods to deal with them. This also agrees with the results of Abdelkarim's study (2015), which revealed the importance of counsel programs in developing some personality aspects between youth, including empathy, conscience, self-control, respect, and tolerance.

There are statistically significant differences among the mean scores of the experimental and control groups in the post-testing of the moral competence scale dimensions. The study confirmed the validity of the second hypothesis. This may be due to the effectiveness of the professional intervention, with its objectives, stages and therapeutic methods, as well as the willingness of the experimental group members to apply program and their conviction of the program's benefit. This is consistent with the studies of Salama Mansour (2008), Abdo Kamel (2013), and Osama Kamal (2017). The studies asserted the effectiveness of the elective approach in increasing youth awareness and providing them with information, experience, and skills that help them change negative behavior to positive behavior. They also increase the youth ability to address their problems, which reflects positively on their social relationships and increased psychological and social adjustment.

There are no statistically significant differences among the mean scores of the pre-and post-testing of the control group on the moral competence scale. The study confirmed the validity of the third hypothesis.

The results of the study confirmed the effectiveness of the elective approach in increasing the moral competence of social workers. This may be due to the cooperation of the social workers with the Authors, their active participation in the program, and following the provided instructions. This is in addition to the commitment of the control group members to applying the various tasks and methods, their acceptance of the direct and indirect therapeutic methods used through the elective approach, and the multiple roles applied during the professional intervention program. 


\begin{tabular}{|lr|}
\hline The Egyptian Journal of Social Work (EJSW) & www.ejsw.org \\
ISSN: 2356-9204 & Vol 1, No.5, January 2018 \\
\hline
\end{tabular}

The social workers welcomed the program, as evidenced by their cooperation and enthusiasm to work on the success of this program and to respond to the methods and strategies that were used with them. Among the most common methods accepted by social workers, psychological aid methods such as emotional appreciation and emotional emptiness. And cognitive methods such as logical discussion, interpretation and cognitive reconstruction. And behavioral methods such as positive reinforcement, homework and modeling. One of the most blurred methods is confrontation and meditation. One of the most positive strategies that has achieved positive results with the social workers the strategy of persuasion, the knowledge acquisition strategy and the education and training strategy. One of the most common skills acquired by social workers the skill of establishing social relationships with the surroundings, skills dealing with stressful situations, and problem-solving skills in the light of moral competencies.

\section{REFERENCES}

Abdelkerim, M. Abdullatif (2015), The Level of Moral Intelligence and Its Relation to Gender and Educational Branch Variables among Secondary School Students in the Jordan Valley Region, Jordan Journal of Educational Sciences, Volume (11), number (1).

Al Ayoub, A. Khalid (2006), Moral Intelligence and How to Develop It, Al Watan Magazine, King Saud University, No. (92).

Al-Rasheed, M. Ahmed (2001), Introduction on Moral Education, Al-Ma'arefa Magazine, No. 72, Riyadh, Ministry of Education.

Al-Tifi, A. (2007), Elective Technics in Individual Service for Developing Creative Thinking Abilities among Children, published in the Journal of Studies in Social Work and Humanities, Faculty of Social Work, Helwan University, Vol. 5, no. 23.

Azab, H. (2002), The Effectiveness of an Integrative Negotiation Program to Overcome Violent Behavior in a Sample of Adolescents, Center for Psychological Counsels Center, Ain Shams University, 9th Annual Conference, Volume 2.

Borba, M (2001), Building Moral Intelligence, The Seven Essential Virtues that Teach Kids to do the Right Thing, San Francisco, Jossey Bass. 


\begin{tabular}{||lr||}
\hline The Egyptian Journal of Social Work (EJSW) & Www.ejsw.org \\
ISSN: $2356-9204$ & Vol 1, No.5, January 2018 \\
\hline
\end{tabular}

Borba, M. (2003), Building Moral Intelligence, translated by Saad Al-Husseini, Al-Ain, University Book House.

El Gharib, Osama (2003): Disturbance Skills of Social Competence of Multiple and Multiplexers, Unpublished Doctoral Thesis, Faculty of Arts, University of Minya.

El Shammari, A. Ali Hassan (2007), Moral Intelligence and its Relation to Mutual Social Trust, Unpublished Master Thesis, Faculty of Arts, University of Baghdad, Iraq.

El TaeI, Maryam (2010): The moral intelligence of middle school students, research published in the Journal of Psychological Sciences, No. (17).

EI Tifi, A. (2004), An Introductory Approach for the Individual to Reduce Social Problems Associated with Early Retirement, Unpublished $\mathrm{PhD}$ Thesis, Faculty of Social Work, Fayoum University, 2004.

EL Zoheiry, M. Saleh (2013), Moral Intelligence and its Relation to Social Tolerance among Middle School Students, Journal of Educational Studies, No. 21.

Golman, Daniel (2000): Emotional Intelligence, laila el gebally, Knowledge World, Issue 262, National Council for Culture, Arts and Letters, Kuwait.

Gullickson, T (2004), The Moral Intelligence of Children, How to Raise a Moral Child, New York, Bantam books.

Hing Keung, Ma (2014), Review Article, Moral Competence as A Positive Youth Development Construct: A Conceptual Review, Middle-East Journal of Scientific Research 19 (9): 1259-1265, IDOSI Publications.

Hoffman. M (1970): Moral Development, Third Edition vol 12, John Wiley and sons, New York.

Jamal, Ahmed, M. (2013), Applying a Protective Program from an Elective Perspective for Prevention of Psychological Harassment among Nurses, published in the Journal of Studies in Social Work and Humanities, Faculty of Social Work, Helwan University, No. 35.

Kamal, O. Mohammed, (2017), The Effectiveness of an Elective Style in Individual Service in Reducing Violent Behavior among High School Students, Unpublished Doctoral Thesis, Faculty of Social Work, Helwan University. 
